\title{
Comparative study of pain in women submitted to conventional laparoscopic cholecystectomy versus single- port laparoscopic cholecystectomy ${ }^{1}$
}

\author{
Júverson Alves Terra Júnior', Guilherme Azevedo Terra", Marisa de Carvalho Borges"', Tharsus \\ Dias Takeutiv", Luciana Garcia Pereira Castro", Simone Souza Limav, Luciane Fernanda Rodrigues \\ Martinho Fernandes ${ }^{v 1}$, Alex Augusto da Silva', Eduardo Crema'
}

'PhD, Full Professor, Department of Surgery, Federal University of Triângulo Mineiro (UFTM), Uberaba-MG, Brazil. Scientific content of the study, technical procedures, critical revision.

"MD, School of Medicine, UFTM, Uberaba-MG, Brazil. Scientific content of the study, manuscript writing, critical revision.

I'PhD, Physiotherapist, Department of Surgery, UFTM, Uberaba-MG, Brazil. Intellectual and scientific content of the study, manuscript writing, critical revision.

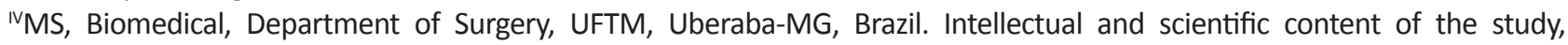
manuscript writing, critical revision.

${ }^{\vee}$ Administrative Analyst, Sabin Laboratory, Brasilia-DF, Brazil. Intellectual and scientific content of the study, critical revision. V'PhD, Physiotherapist, Department of Physiotherapy, UFTM, Uberaba-MG, Brazil. Intellectual and scientific content of the study, manuscript writing, critical revision

\begin{abstract}
Purpose: To evaluate postoperative pain in patients submitted to conventional laparoscopic cholecystectomy with four ports versus single-port laparoscopic cholecystectomy with only one port.

Methods: Twenty-one patients were included in the conventional laparoscopic cholecystectomy group and 19 other patients in the single-port laparoscopic cholecystectomy group. A VAS was used for the assessment of postoperative pain at three time points. Differences were considered statistically significant when $p<0.05$.

Results: Intergroup analysis showed no significant difference in VAS scores between the conventional laparoscopic cholecystectomy and single-port laparoscopic cholecystectomy groups at any of the time points studied.

Conclusion: This study found no significant difference in postoperative pain between the two groups.
\end{abstract}

Key words: Cholelithiasis. Cholecystectomy, Laparoscopic. Pain 


\section{- Introduction}

Laparoscopic cholecystectomy has become the standard surgical intervention for patients with benign gallbladder disease ${ }^{1}$. After several technical modifications made over decades, a single incision in laparoscopic cholecystectomy has been described as an alternative procedure in an attempt to reduce surgical trauma, to improve esthetic outcomes, and to reduce complication rates at the incision site and postoperative pain ${ }^{2,3}$.

Pain is the most common complication or discomfort during the postoperative period. The intensity of pain depends on physiological factors such as the extent of trauma, surgical intervention, the surgeon's technical skills, previous diseases and the site and type of incision; psychological factors such as anxiety and fear, and cultural factors of the patient ${ }^{4,5}$.

The evaluation of postoperative pain using a Visual Analogue Scale (VAS) is a simple and efficient tool to measure the intensity of pain. This scale is widely used in clinical practice and laboratories to guide the decisionmaking of professionals so that adequate therapeutic measures can be provided, possible complications can be prevented, and early recovery of patients can be achieved ${ }^{6,7}$.

The aim of the present study was to evaluate postoperative pain using a unidimensional VAS in women submitted to conventional laparoscopic cholecystectomy (CLC) with four ports versus single-port laparoscopic cholecystectomy (SPLC) in which only a single incision is made in the umbilical region.

\section{Methods}

The study was approved by the Research Ethics Committee of Universidade Federal do Triângulo Mineiro (Permit No. 2503).

$$
\text { A prospective, cross-sectional, }
$$
randomized study was conducted at the
Department of Digestive Tract Surgery, Central Hospital, UFTM. Forty women with symptomatic cholelithiasis ranging in age from 18 to 70 years participated in the study. The patients were divided into two groups: 21 were submitted to CLC and 19 to SPLC.

The data of each patient were recorded on an assessment form that contained information such as age, anthropometric variables (weight, height, body mass index $\mathrm{BMI})$, risk factor for cholelithiasis, and duration (minutes) of the surgical procedures.

Women with symptomatic cholelithiasis older than 18 years, who were able to understand the objective of the study and to give informed consent, were included in the study. Criteria for exclusion were: pregnancy; $\mathrm{BMI}>35 \mathrm{~kg} / \mathrm{m}^{2}$; presence of systemic diseases; use of medications that would interfere with the immune response; a suspicion or confirmation of liver cirrhosis; coagulopathy (platelet count $<50,000 / \mu \mathrm{l}$ ); antiplatelet therapy (acetylsalicylic acid and clopidogrel); acute pancreatitis, and jaundice.

\section{Surgical procedure}

Anesthesia was standardized as follows: pre-anesthetic medication administered 3 hours before surgery, which consisted of oral diazepam (10 mg), intravenous midazolam (5 mg) and volume expansion with 1,000 ml saline; induction of anesthesia: alfentanil (30 $\mathrm{mg} / \mathrm{kg})$, etomidate $(0.3 \mathrm{mg} / \mathrm{kg})$ and atracurium $(0.5 \mathrm{mg} / \mathrm{kg})$; maintenance of anesthesia: continuous infusion of alfentanil (1 mg/kg/ $\mathrm{min}$ ) and isoflurane (0.5-1.5\%); decurarization: intravenous atropine ( $1 \mathrm{mg}$ ) and prostigmin (2 $\mathrm{mg})$.

\section{Conventional laparoscopic cholecystectomy}

The patient was placed in horizontal dorsal decubitus on the operating table and received general anesthesia. Perioperative 
monitoring consisted of cardioscopy, noninvasive blood pressure monitoring, pulse oximetry, and capnography. A pressure of $12 \mathrm{mmHg}$ was used for maintaining pneumoperitoneum.

Conventionallaparoscopiccholecystectomy consisted of the insertion of four trocars, one 10$\mathrm{mm}$ trocar was inserted in the supraumbilical region for placement of the optical system and a 5-mm one was inserted in the right flank for cranial traction of the gallbladder. The other two working trocars were placed in the same line, a 5-mm trocar was inserted in the right upper quadrant for removal of the gallbladder and the other $10-\mathrm{mm}$ one was placed in the epigastrium, at the left side of the round ligament, for dissection and hemostasis.

The hilum was exposed by lateral retraction, holding the infundibulum and retracting it to the right and downwards. The cystic duct was isolated, ligated, and sectioned. Next, the cystic artery was identified, isolated, and clipped with metal clips. The gallbladder was then removed from the liver bed.

\section{Single-port laparoscopic cholecystectomy}

The position of the patients and of the surgical team, as well as anesthesia and position of the monitor, was similar to that employed in CLC. A 2-cm transumbilical horizontal incision was made, followed by dissection, opening of the aponeurosis and peritoneum, and placement of a single port (SILS port). Pneumoperitoneum was induced and maintained at $12 \mathrm{mmHg}$. Trocars were placed through the single port, including two trocars of $5 \mathrm{~mm}$ and one of $10 \mathrm{mmHg}$ for introduction of the 300 optic. Conventional laparoscopy materials were used.

After good exposure of the triangle of the bile duct with the aid of a wire passed through the gallbladder infundibulum, dissection, clipping and sectioning of the cystic duct and cystic artery were performed using the same materials as employed in conventional laparoscopy. For clipping, the $5-\mathrm{mm}$ trocar was changed to a $10-\mathrm{mm}$ one introduced in the position. The gallbladder was then dissected from the infundibulum to the fundus.

\section{Pain assessment}

Pain was assessed by the Physiotherapy team responsible for the Digestive Surgery nursing ward of UFTM's Central Hospital. A VAS consisting of a $10-\mathrm{cm}$ long strip marked "no pain" at one end and "unbearable pain" at the opposite end was used for pain assessment. The values in centimeters are recorded on the back of the strip. Women mark their answer perpendicular to the line referring to the pain experienced on that occasion and the examiner later verifies the corresponding value on the back.

During hospitalization of the women in the nursing ward, pain was assessed at three different time points: T1 (first immediate postoperative assessment $-6 \mathrm{~h}$ ); T2 (second immediate postoperative assessment - 12 h), and T3 (first postoperative day - $24 \mathrm{~h}$ ). The researchers that assessed pain had no prior knowledge of the surgical technique performed.

\section{- Results}

Table 1 shows the mean \pm standard deviation of the anthropometric variables and age of women submitted to CLC and SPLC. There was a significant difference in height between the two groups $(p=0.022)$, but this anthropometric variable is not related to gallstone formation.

With respect to the smoking habit questioned in the initial protocol, three $(14.3 \%)$ patients in the group undergoing CLC and six (31.6\%) in the SPLC group were smokers. 
Table 1 - Mean \pm standard deviation of the anthropometric variables and age of women submitted to CLC and SPLC.

\begin{tabular}{|c|c|c|c|}
\hline Variable & $\mathrm{CLC}$ & SPLC & $p$ value \\
\hline Age & $\begin{array}{c}38.38 \pm \\
11.72\end{array}$ & $\begin{array}{c}34.21 \pm \\
10.51\end{array}$ & NS \\
\hline Weight (kg) & $\begin{array}{c}69.40 \pm \\
16.76\end{array}$ & $\begin{array}{c}64.81 \pm \\
9.63\end{array}$ & NS \\
\hline Height (m) & $\begin{array}{c}1.57 \pm \\
0.07\end{array}$ & $\begin{array}{c}1.62 \pm \\
0.04\end{array}$ & 0.0220 \\
\hline $\mathrm{BMI}\left(\mathrm{kg} / \mathrm{m}^{2}\right)$ & $\begin{array}{l}27.90 \pm \\
6.52\end{array}$ & $\begin{array}{l}24.52 \pm \\
3.67\end{array}$ & NS \\
\hline
\end{tabular}

CLC: conventional laparoscopic cholecystectomy; SPLC: singleport laparoscopic cholecystectomy; NS: nonsignificant; BMI: body mass index. Sex was compared by Fisher's exact test and numerical variables, expressed as mean \pm standard deviation, were compared by the Student t-test.

\section{Results of pain assessment}

Median pain scores were lower in the SPLC group at $\mathrm{T} 1$ and $\mathrm{T} 2$, while the values were similar at $\mathrm{T} 3$. A reduction in pain at the three time points was observed in both groups (Figure 1).

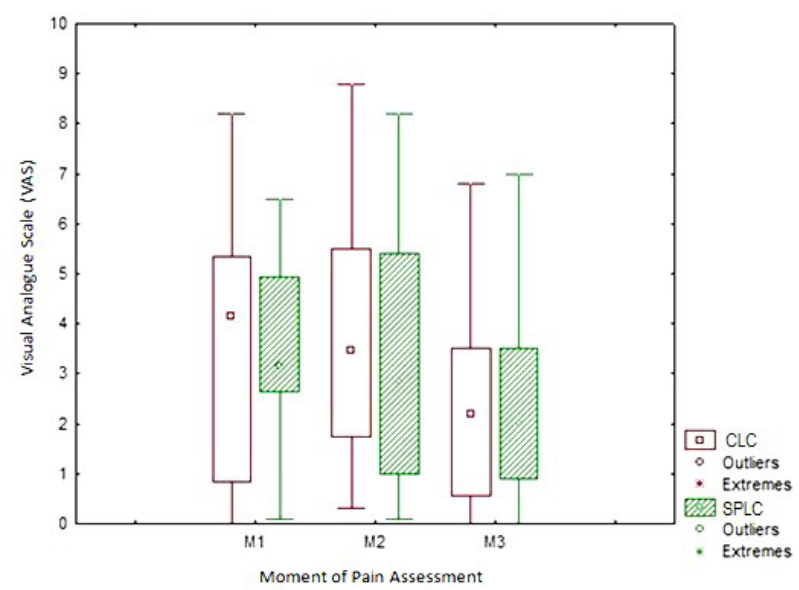

Figure 1 - Boxplot of Visual Analogue Scale (VAS) scores at the three different times of pain assessment in the conventional laparoscopic cholecystectomy (CLC) and single-port laparoscopic cholecystectomy (SPLC) groups.
Intergroup analysis revealed no significant difference in VAS scores between the CLC and SPLC groups at any of the time points studied (Table 2).

Table 2 - Mean, standard deviation and median Visual Analogue Scale (VAS) scores at each time point of pain assessment in the two groups.

\begin{tabular}{ccccc} 
VAS & Group & Mean $( \pm S D)$ & Median & p value \\
T1 & CLC & $3.63( \pm 2.47)$ & 4.15 & \\
& SPLC & $3.51( \pm 1.7)$ & 3.15 & 0.807 \\
& CLC & $3.73( \pm 2.51)$ & 3.45 & 0.432 \\
T2 & SPLC & $3.14( \pm 2.66)$ & 2.85 & \\
& CLC & $2.33( \pm 1.94)$ & 2.20 & 0.935 \\
T3 & & $2.3( \pm 1.84)$ & 2.00 & \\
\hline
\end{tabular}

CLC: conventional laparoscopic cholecystectomy; SPLC: single-port laparoscopic cholecystectomy. T1: first immediate postoperative assessment; $\mathrm{T} 2$ : second immediate postoperative assessment; T3: first postoperative day. Intragroup analysis: $p$ value obtained by the nonparametric Mann-Whitney $U$ test for independent samples (CLC X SPLC) at the three time points.

Intragroup analysis showed a significant decrease in VAS scores between T1xT3 and T2xT3 for the CLC group and between T1xT3 for the SPLC group $(p \leq 0.05)$ (Table 3$)$.

Table 3 - Intragroup comparison of Visual Analogue Scale (VAS) scores between the different time points of pain assessment in each group.

\begin{tabular}{ccc} 
& CLC & SPLC \\
T1xT2 & $\mathrm{p}=0.747$ & $\mathrm{p}=0.546$ \\
T1xT3 & $\mathrm{p}=0.007^{*}$ & $\mathrm{p}=0.008^{*}$ \\
T2xT3 & $\mathrm{p}=0.002^{*}$ & $\mathrm{p}=0.227$ \\
\hline
\end{tabular}

CLC: conventional laparoscopic cholecystectomy. SPLC: single-port laparoscopic cholecystectomy. T1: first immediate postoperative assessment; $T 2$ : second immediate postoperative assessment; T3: first postoperative day. ${ }^{*} p \leq 0.05$ significant by the nonparametric Wilcoxon t-test for paired samples. 
In the present study, there was no case of conversion from CLC to SPLC in either group.

\section{- Discussion}

The trauma resulting from surgical proceduresinvolves physiologicalandemotional changes that, if not properly controlled, may predispose patients to complications and may extend hospitalization. Pain is an important condition that can affect a patient's recovery ${ }^{8}$.

Pain assessment aims to identify the existence of pain and to establish the etiology of symptoms. In this respect, it is important to characterize the pain experience in all its domains, to assess the impact of pain on organic, emotional and behavioral functioning of the individual, to identify factors that contribute to the maintenance or exacerbation of pain, to select treatment alternatives, and to verify the effectiveness of the therapies employed. Systematically conducted and recorded assessments, which use specific scales to characterize and measure the pain condition, may contribute to improve the management of the painful experience ${ }^{9}$.

Laparoscopy was introduced in 1987 and has since then been used for multiple intraabdominal procedures because of the reduced patient discomfort, shorter hospitalization time and early return to work ${ }^{10}$. These advantages have led to the increased use of laparoscopy for the diagnosis and treatment of patients admitted in emergency departments with abdominal pain ${ }^{11}$.

Werner and Kehlet $^{12}$ conducted a systematic review of postoperative predictors of pain and concluded that studies point to a significant relationship between the type of surgical approach and the intensity and duration of postoperative pain.

For this study, two groups of women undergoing CLC and SPLC were submitted to postoperative pain assessment with a VAS at three time points: T1 (first immediate postoperative assessment), T2 (second immediate postoperative assessment), and T3 (first postoperative day). Median VAS scores were found to be lower in the group submitted to SPLC at T1 and T2, while similar values were observed for the two groups at T3.

There is no consensus in the literature regarding the results of postoperative pain in patients undergoing single-port surgery. Lower levels of pain have been reported by patients submitted to minilaparoscopy compared to those submitted to laparoscopy ${ }^{13}$. However, due to the subjectivity of the assessment, the results of most studies are inconclusive ${ }^{14}$.

Caumo et al. ${ }^{15}$, studying 346 patients submitted to elective abdominal surgery, observed a prevalence of moderate to intense pain (VAS $>30 \mathrm{~mm}$ ) in $43.4 \%$ of the patients in the first $24 \mathrm{~h}$ after surgery. In a study carried out in 2003 on the prevalence of postoperative pain, Sommer et al. ${ }^{16}$ observed that $30 \%$ to $55 \%$ of patients of the abdominal surgery subgroup reported moderate to intense pain (VAS >40 $\mathrm{mm}$ ) on the day of surgery and on the first postoperative day.

The present study included only women. According to Kowalczyka et al. ${ }^{17}$, women report more pain and estrogen is responsible for this increased perception of pain. Furthermore, women are more sensitive to pain during the menstrual period and during menopause if they receive hormone replacement therapy. The authors suggested that the increase in luteinizing hormone during the luteal phase of the menstrual cycle reduces endogenous opioids, increasing sensitivity.

Several factors may affect postoperative pain such as sex, age, size of the wound, and recovery time of gastrointestinal function. In the study of Guo et al. ${ }^{18}$, no significant differences in pain assessment were observed between patients undergoing traditional laparoscopic cholecystectomy and single-port surgery 24h, 7 days or 1,3 or 6 months after surgery. Pain scores were significantly lower only $6 \mathrm{~h}$ after surgery in the group treated by SPLC compared to the group submitted to laparoscopic 
cholecystectomy. However, when placing this 1-point difference on a 10-point scale, there seemed to be no significant change in clinical practice. In the present study, intergroup analysis showed no significant difference in VAS scores between the SPLC and CLC groups at any of the time points, while intragroup analysis revealed a significant decrease in VAS scores between T1xT3 and T2xT3 for the CLC group and between T1xT3 for the SPLC group ( $\leq \leq 0.05$ ).

Yin et al. $^{19}$ assessed the intensity of postoperative pain at rest using a numerical rating scale. Pain intensity was assessed immediately and 6, 24 and 48h after the surgical procedures. The results of that study agree with the present findings since the authors did not observe significant differences in the intensity of pain between the laparoscopic cholecystectomy and singleport access laparoscopy groups. In contrast, Kim et al. ${ }^{20}$ reported advantages for patients submitted to SPLC compared to laparoscopic cholecystectomy using a VAS to measure pain $24 \mathrm{~h}$ after surgery.

\section{Conclusions}

The results of the present study showed no significant difference in postoperative pain between the groups submitted to conventional laparoscopic cholecystectomy and single-port laparoscopic cholecystectomy.

\section{References}

1. Terho PM, Leppäniemi AK, Mentula PJ. Laparoscopic cholecystectomy for acute calculous cholecystitis: a retrospective study assessing risk factors for conversion and complications. World J Emerg Surg. 2016 Nov 16;11:54. doi: 10.1186/s13017-016-0111-4. PMID: 27891173.

2. Far SS, Miraj S. Single-incision laparoscopy surgery: a systematic review. Electron Physician. 2016 Oct 25;8(10):3088-95. Review. doi: 10.19082/3088.

3. Matsui Y, Yamaki S, Hirooka S, Yamamoto T,
Yanagimoto H, Satoi S, Kon M. Evaluation of relative criteria for single-incision laparoscopic cholecystectomy. Asian J Surg. 2016 Dec 5. doi: 10.1016/j.asjsur.2016.11.002.

4. Wennmacker $S$, Lamberts $M$, Gerritsen J, Roukema JA, Westert G, Drenth J, van Laarhoven C. Consistency of patient-reported outcomes after cholecystectomy and their implications on current surgical practice: a prospective multicenter cohort study. Surg Endosc. 2017 Jan;31(1):215-24. doi: 10.1007/ s00464-016-4959-x.

5. Chong JU, Lee JH, Yoon YC, Kwon KH, Cho JY, Kim SJ, Kim JK, Kim SH, Choi SB, Kim KS. Influencing factors on postoperative hospital stay after laparoscopic cholecystectomy. Korean J Hepatobiliary Pancreat Surg. 2016 Feb;20(1):12-6. doi: 10.14701/ kjhbps.2016.20.1.12.

6. Onaka $H$, Ishikawa M, Mizuguchi $Y$, Uchida $E$, Sakamoto A. Evaluation of postoperative pain control and quality of recovery in patients using intravenous patient-controlled analgesia with fentanyl: a prospective randomized study. J Nippon Med Sch. 2016;83(4):158-66. doi: 10.1272/jnms.83.158.

7. Colliver J, Wang A, Joss B, Ebert J, Koh E, Breidahl W, Ackland T. Early postoperative repair status after rotator cuff repair cannot be accurately classified using questionnaires of patient function and isokinetic strength evaluation. J Shoulder Elbow Surg. 2016 Apr;25(4):536-42. doi: 10.1016/j. jse.2015.09.019.

8. Beck C, Eakin J, Dettorre R, Renton D. Analysis of perioperative factors and cost comparison of single-incision and traditional multiincision laparoscopic cholecystectomy. Surg Endosc. 2013 Jan;27(1):104-8. doi: 10.1007/ s00464-012-2428-8.

9. Schwenkglenks M, Gerbershagen HJ, Taylor RS, Pogatzki-Zahn E, Komann M, Rothaug J, Volk T, Yahiaoui-Doktor M, Zaslansky R, Brill S, Ullrich K, Gordon DB, Meissner W. Correlates of satisfaction with pain treatment in the acute postoperative period: results from the international PAIN OUT registry. Pain. 2014 Jul;155(7):1401-11. doi: 10.1016/j. pain.2014.04.021. 
10.Guller $U$, Hervey S, Purves $H$, Muhlbaier $\mathrm{LH}$, Peterson ED, Eubanks S, Pietrobon R. Laparoscopic versus open appendectomy: outcomes comparison based on a large administrative database. Ann Surg. 2004 Jan;239(1):43-52. doi: 10.1097/01. sla.0000103071.35986.c1.

11.Saia M, Mantoan D, Buja A, Bertoncello C, Baldovin T, Callegaro G, Baldo V. Time trend and variability of open versus laparoscopic cholecystectomy in patients with symptomatic gallstone disease. Surg Endosc. 2013 Sep;27(9):3254-61. doi: 10.1007/ s00464-013-2902-y.

12. White PF, Kehlet $H$, Werner PF, Kehlet $H$. Improving postoperative pain management: what are the unresolved issues? Anesthesiology. 2010 Jan;112(1):220-5. doi: 10.1097/ALN.0b013e3181c6316e.

13..Mamazza J, Schlachta CM, Seshadri PA, Cadeddu MO, Poulin EC. Needlescopic surgery. A logical evolution from conventional laparoscopic surgery. Surg Endosc. 2001 Oct;15(10):1208-12. doi: 10.1007/ s004640080024. 7102.

14.Look M, Chew SP, Tan YC, Liew SE, Cheong DM, Tan JC, Wee SB, Teh CH, Low CH.Post-operative pain in needlescopic versus conventional laparoscopic cholecystectomy: a prospective randomised trial. J R Coll Surg Edinb. 2001 Jun;46(3):138-42. PMID: 11478009.

15.Caumo W, Schmidt AP, Schneider CN, Bergmann J, Iwamoto CW, Adamatti LC, Bandeira D, Ferreira MB. Preoperative predictors of moderate to intense acute postoperative pain in patients undergoing abdominal surgery. Acta Anaesthesiol Scand. 2002;46(10):1265-71. PMID: 12421200.

16.Sommer M, de Rijke JM, van Kleef M, Kessels AG, Peters ML, Geurts JW, Gramke HF, Marcus MA. The prevalence of postoperative pain in a sample of 1490 surgical inpatients. Eur J Anaesthesiol. 2008;25(4):267-74. doi: $10.1017 /$ S0265021507003031.

17.Kowalczyk WJ, Sullivan MA, Evans SM, Bisaga AM, Vosburg SK, Comer SD. Sex differences and hormonal influences on response to mechanical pressure pain in humans. J Pain. 2010 Apr;11(4):330-42. doi: 10.1016/j. jpain.2009.08.004.

18.Guo W, Liu Y, Han W, Liu J, Jin L, Li JS, Zhang ZT. Randomized trial of immediate postoperative pain following single-incision versus traditional laparoscopic cholecystectomy. Chin Med J (Engl). 2015 Dec 20;128(24):33106. doi: 10.4103/0366-6999.171422.

19.Yim GW, Lee M, Nam EJ, Kim S, Kim YT, Kim SW. Is single-port access laparoscopy less painful than conventional laparoscopy for adnexal surgery? A comparison of postoperative pain and surgical outcomes. Surg Innov. 2013 Feb;20(1):46-54. doi: $10.1177 / 1553350612439632$.

20.Kim TJ, Lee YY, NA JJ, Choi CH, Lee JW, Kim BG, Bae DS. Does single-port access (SPA) laparoscopy mean reduced pain? A retrospective cohort analysis between SPA and conventional laparoscopy. Eur. J. Obstet. Gynecol. Reprod. Biol. 2012 May;162(1):71-4. doi: 10.1016/j.ejogrb.2012.01.007.

\section{Correspondence:}

Eduardo Crema

Rua Marcos Lombardi, 305

38050-170 Uberaba - MG Brasil

Tel.: (55 34)3318-5228

cremauftm@mednet.com.br

Received: Feb 23, 2017

Review: Apr 25, 2017

Accepted: May 26, 2017
Conflict of interest: none

Financial sources: FAPEMIG, CNPq, FUNEPU, UFTM.
${ }^{1}$ Research performed at Department of Surgery, University Hospital, Universidade Federal do Triângulo Mineiro (UFTM), Uberaba-MG, Brazil. 